\title{
A Sign in Twilight: Semiotic Interpretations of Sandhayabhasha Metaphors in the Charyapada
}

\author{
UPAMANYU SENGUPTA
}

This paper offers a semiotic model of interpretation of metaphors used in the Charyapada - a collection of Buddhist religious verses in Bangla composed between tenth and twelfth centuries. Drawing from conflicting attributions of concealment through sandhyabhasha or twilight language and revelation through sandhayabhasha or intentional speech as the primary function of the verses, I propose a Peircean threefold model of reading their metaphors as iconic, indexical and symbolic. A.K. Ramanujan's adoption of the Peircean tripartite classification for translation types serves as the frame of reference.

Keywords: metaphors, sandhayabhasha, iconic, indexical, symbolic.

\section{Introduction}

Consisting of about fifty lyrical verses composed by monks of the sahajiya school of Buddhism between tenth and twelfth centuries, the Charyapada, ${ }^{1}$ features an obscure metaphorical diction. Following Mahamahopadhyaya Haraprasad Shastri's discovery of the manuscript in 1907 at the royal palace library in Kathmandu in Nepal, two competing strains of opinion emerged about the semantics of this arcane language. Given the part revelatory and part concealing nature of the metaphors, Shastri (1916: 8) went on to call the resulting language sandhyabhasha or 'twilight language' — an encrypted code meant to conceal complex spiritual knowledge from the laity. Over the years, in the Bengali academic community, Shastri's coinage and the meaning he ascribed to it gained wider currency. However, in 'Sandhabhasa', published more than a decade after Shastri's discovery, Vidhushekhara Bhattacharya (1928: 288) refuted his claim and argued for replacing the prefix sandhya with sandha - a shortened form of sandhaya. According to him, the terms are synonymous with sandhya, with equivalents like uddisya, abhipreya and abhisandhaya in Sanskrit. All of these, including sandha, could be translated

\footnotetext{
${ }^{1}$ Shastri's claim of the language of these manuscripts as Bangla (1916: 7-18), triggered considerable debate among scholars of other languages derived from Magadhi Prakrit such as Odia and Assamese. Mojumdar discusses these debates in detail (p 97-103) and brings out the equally convincing arguments put forth while making claims on behalf of each language. I am indebted to Dr. Niladri Sekhar Dash and Professor Panchanan Mohanty for drawing my attention to the difficulty of imputing a single modern language to a text such as Charyapada which were composed well before neatly demarcated linguistic identities across these languages get instituted.
} 
variously as 'aiming at', 'meaning', 'having in view or 'intending towards'. Citing sources from Tibetan Buddhism and sahajiya schools, ${ }^{2}$ Bhattacharya identified these metaphors as mediums of making the esoteric meaning accessible instead of deflecting one's attention away from them. Thus, while Shastri focused primarily on the perceived opacity of the metaphorical language, Bhattacharya foregrounded its revelatory dynamic.

The two competing, if also interrelated, techniques of interpreting furnished by both sandhyabhasha and sandhayabhasha hinge on the relationship between the literal and metaphorical meaning in the charya verses. In each case, the metaphorical meaning consists in differing degrees of semantic variation on the literal language. It is against this background that the paper maps the resulting relational structures into a tripartite classification of the metaphors as ICONS, INDICES and SYMBOLS. This is derived from Charles Sanders Peirce's division of signs into the mentioned categories and the adoption of the same as a model for translation types by A. K. Ramanujan. In what follows, I attempt brief explanations of the Peircean classification as well as Ramanujan's adoption of the same with reference to pointers that would be of relevance to the present discussion on the language of the charyas. The feasibility of recasting the differing interpretations of the metaphors furnished by sandhyabhasha and sandhayabhasha as three types of signs is explored in the subsequent sections along with illustrations. For my reading of the verses, I rely on a rendering of the Charyapada in modern Bangla by Atindra Mojumdar.

\section{Peircean Semiotic Framework and its Adoption by Ramanujan}

For Peirce (2011:104), a sign (henceforth also called signifier) and the object (henceforth also called signified) it signifies, are related to each other in three possible ways: icons, indices and symbols. Thus, an iconic signifier bears a relationship of exact likeness or resemblance or what Peirce calls 'firstness, 3 with its signified. A signifier is indexical when it assumes its signifying function by virtue of being affected by the signified, and thus, in a sort of back formation, refers back to the signified as the cause of its coming into being. Peirce (2011:108) describes the indexical signifier as one which 'direct(s) the attention to their objects by blind compulsion'. A symbolic signifier, on the other hand, has no intrinsic quality that makes possible the signifying function and its relation with the signified is purely a matter of convention and practice. It is because of this arbitrary coupling that Peirce (2011: 113) describes the relationship as one of being 'thrown together'.

\footnotetext{
${ }^{2}$ Apart from the Dohakosa by Sarojavajra in the sahajiya tradition, the Tibetan sources include $\mathrm{L}$

ankavatara, and Saddharmapundarika,

${ }^{3}$ It might be worthwhile to consider Peirce's exact words in this regard. He describes firstness "as a quality it has qua thing [that] renders it fit to be a representamen. Thus, anything is fit to be a Substitute of anything it is like" (2011: 104). [Original emphasis]. 198
} 
In his essay "Three hundred Ramayanas: Five examples and three thoughts on translations", Ramanujan (2006: 156) identifies translation as a mode of imagining relationships among the diverse Ramayana stories across Central, South and Southeast Asia. Terming these as 'tellings', ${ }^{4}$ he maps the differential relations among them in terms of the classification of signs into icons, indices and symbols. Texts aspiring to be 'faithful' translations are identified as bearing an iconic relationship to the source. Using a Peircean analogy, he describes such texts as showing a 'geometrical resemblance' to each other even if they are limited solely to the structural and episodic levels like in the Kamban and Valmiki tellings of Ramayana. On the other hand, inflections in Ramayana stories caused by changes across locales, cultures and settings in which they get narrated, lead to indexical translations for Ramanujan (2006: 157). All such tellings are affected by the environs in which they take shape and 'are embedded in a locale, a context, refers to it, even signifies it, and would not make much sense without it'. For the charya verses too, it is this aspect of referentiality which is critical to understanding the nature of metaphorical usage in them. In symbolic translations, Ramanujan (2006: 157) recognises the subversive potential new tellings Ramayana stories might carry. These radically reinvent the existing narratives by 'producing a counter-text', thereby setting up one set of conventions against another. The signifier-signified relationships across tellings are readjusted by 'mapping a structure of relations onto another plane or another symbolic system' in a classic example of the Peircean paradigm of being 'thrown together'.

\section{Three Stages of Interpretation}

I shall now focus on recasting the dyadic relationship between literal language and metaphorical meaning in the charya verses in terms of the semiotic structure encompassing icons, indices and symbols. As is shown in this section, it is possible to read each of the three interpretive relationships in the verses, and the overlaps across them posit these as simultaneous stages of interpretation rather than types. At the level of metaphors, these are reflected in course of alternating spells of departure from and conformity with the literal meaning of the verses. This simultaneity is of especial consequence in view of the oppositional as well as complementary relation between sandhyabhasha and sandhayabhasha.

Of the three kinds of signifiers, it is the iconic which exhibits a degree of certitude to the extent that an inherent quality of the sign determines its

\footnotetext{
${ }^{4}$ Ramanujan's choice of the expression 'tellings' underscores the plurality of Ramayana narratives existing side by side and simultaneously instead of being necessarily derived from a single source. To quote him, "I have come to prefer the term telling to the usual terms versions or variants because the latter terms can and do imply that there is an invariant, an original or Ur-text - usually Valmiki's Sanskrit Ramayana, the earliest and most prestigious of them all. But as we shall see, it is not always Valmiki's narrative that is carried from one language to another" (2006: 134).
} 
signifying function. There is something in its physical structure, in the way it appears, that resembles and hence claims to stand for the signified. The icon derives its strength from its very materiality as its tangible existence forecasts the abstract. As a signifier, the icon therefore substitutes the signified by replication and fulfills the condition of 'firstness' ascribed to it by Peirce. This is also true of Ramanujan's criteria of fidelity in translations across 'tellings' where the target text faithfully concurs with the original, keeping changes at a minimum, and involving a reproduction of the source material in a different idiom. The stability of the icon however, comes at a price as it closely emulates and represents what it in fact is not.

In the charya verses, the icon is the literal text and its denotative meaning. Composed in a language both revelatory as well as cryptic, it exemplifies the double-edged self-referentiality of the icon. As a pronounced material presence in language, it stands for an abstraction that can only be implied and never articulated. The inchoate flow of mismatched words that characterises such verses is in fact a faithful reflection of their inexplicability. The literal language, thus represents a level of esoteric spiritual realisation that cannot be grasped in its materiality. As a signifier then, the literal language of the verses both affirms as well as effaces their own being in every instance. For example, in charya 15, when the course of a river is made to suggest the path to salvation, its unidirectional and unwavering nature is given prominence. To the extent that the literal language here functions as sandhyabhasha, or the obscure encryption aimed at deceiving the laity, it brings about a textual closure and projects its own primacy. To the initiated, the iconic function of sandhyabhasha is of diminished importance but also a facsimile representation of a higher order signified. When Shastri posits sandhyabhasha as encrypted language, he attributes it, an opacity meant to cloak substantive religious instruction. While serving as deterrence, this offered a glimpse at the same time into the deeply spiritual recesses of the tantric sahajiya tradition. The flow of meaning between the signifier and the signified is then decidedly unilateral in case of the literal language of sandhyabhasha understood as an iconic sign. Despite its primacy, such a sign does not serve as the preserve of meaning but provides stable cues for it.

Interpreting the literal language of the charya verses as indexical signs marks a departure from the trope of stable signifier. What makes signification possible in such a case is a relationship of referentiality that may be posited between the literal and metaphorical meanings of the verses. This fits particularly well with Bhattacharya's (1928: 293) definition of sandhayabhasha as 'abhiprayikavacana' or 'intentional speech'. The literal signifier in this case aims at, intends, and is oriented towards the metaphorical meaning contained in the signified. Unlike in case of the icon, the relation is not one of discernible resemblance but implicit and implied. As Bhattacharya contends (1928: 293), the charya verses align themselves to the neyartha mode of teaching in Buddhism characterised by indirectness. The signification therefore, is not immediately visible but needs to be deduced and 200 
arrived at by means of cues the signifier has on offer. Thus, while the icon is distinguished by its fixity, the index, in that it points and is oriented towards a destination, schemes its way to the signified. The literal language as a signifier in this case emerges as a continually shifting, altering space of meaning making. In doing so, it commutes the meaning instead of manifesting it as something immanent. This involves an exercise of reaching out and eliciting the metaphorical meaning couched in what Bhattacharya, citing the translator scholar Eugene Burnouf, calls 'enigmatical talk' of the verses (1928: 288). The obscurity in case of sandhayabhasha however, is not a means of eclipsing the meaning, but a suggestive trigger leading to inferences at the metaphorical level. Unlike the iconic signifier, the indexical sandhayabhasha is not self- referential but draws our attention away from itself.

Indexical signification in sandhayabhasha thus proceeds by means of discovering proximity between terms that had hitherto appeared remote. As noted by Paul Ricoeur (1978: 147), this establishment of kinship between heterogeneous ideas in poetry also informs the Aristotelean idea of epiphora-often regarded as a predecessor to metaphor and all figures of similarity. At the same time, this kinship is fraught with tension as it comes to be meaningful only to the extent that the element of remoteness remains preserved and discernible within the newly formed proximity. In a marked departure from the icon, signification in the indexical mode for sandhayabhasha thrives on throwing in focus the dissimilarities extant between the signifier and the signified. This is also a consequence of the referential function the index assumes as it gets impacted by the signified. Its signification then, proceeds by way of a back formation, and triggers a twoway referentiality, where the signifier derives as much meaning from the signified as it imputes.

Signification ascribed by means of conventions and practices make symbolic sign systems particularly susceptible to such dynamic, two-way movements between the signifier and signified. In fact, what in indexical sandhayabhasha was merely a function of referentiality, evolves into a fullfledged exercise of meaning formation in the symbolic medium. Here the signified metaphorical meaning not only refers back to the literal language of the text, but also crucially influences and alters its meaning. In fact, it is the conventionality of the symbolic signifier that makes it more amenable to subversive readings arising out of the signified. In the context of the charya verses then, the metaphor as a symbol is continually modified, and in a complete reversal from the iconic, the meaning does not get commuted towards the signified alone but is retraced to the signifier in a form determined by the signified. As a result, the signifier comes to acquire a more substantive function and ceases to be a mere vehicle for conveying meaning emerging out of the signified. It becomes, in other words, an active participant in the meaning making process. In the charya verses, each occurrence of a metaphor as a symbolic code comes with a tacit acknowledgement of the 
conventional nature of the relation. The arbitrary nature of any such conventional practice creates a scope for alteration, and what gets altered is also the literal language as it takes on a new meaning. As opposed to the previous instances of iconic or indexical relationships, the literal statement in the symbolic mode is no longer a diminutive accompaniment to the meaning formation through metaphor. Here, the symbolic code infuses the literal with metaphorical meaning and in doing so, transforms it. It is in the symbolic mode then, that the dissociation between the signifier and signified is most decisively overturned and the literal too gains traction.

The two-way exchange of meanings that the literal and metaphorical language in the charya sets up remains rife with tensions. Unlikely points of similarity are drawn between incongruent elements, resulting in a situation where a contemplation of likeness is, as Ricoeur (1978: 148) puts it, "the perception of the conflict between previous incompatibility and the new compatibility". This tension is of utmost importance for the metaphor to fulfill its task of creating what W. Bedell (quoted in Ricoeur 1978: 154) calls "stereoscopic vision" or a projection of radical possibilities of redescribing the world. It is in this act of envisioning that the spiritual import of the charya songs come to the fullest realisation as the ordinary understanding of reality is held in suspension to make way for a "positive insight into the potentialities of our being in the world which our everyday transactions with manipulable objects tend to conceal" (Ricoeur 1978: 155). Such an understanding, in fact, marks a remarkable departure from relegating the literal language of the charya verses as redundant and bereft of substantive meaning. In doing so, it entrusts the readers the task of creatively engaging with the new meaning generated by the displacement in context a metaphor brings about. The hermetic diction of the sandhayabhasha is a consequence of this displacement achieved by, to use the words of Nelson Goodman, "a transfer of a schema, a migration of concepts, an alienation of categories" (Goodman quoted in Fogelin 2011: 72).

\section{Two Illustrations}

Now that we have seen the three stages of metaphors at work in the Charyapada, viz. iconic, indexical and symbolic, it is imperative to consider a few instances from the verses where they might be read into. In charya number 49 by Bhusukupada, the imagistic motif of riverine navigation dominates as the composer urges the audience to recognise the blurred boundaries between seemingly defined and demarcated oppositional categories of existence. The lyrical persona provides an account of sailing his 'vajranauka' or thunderboat across the canal to Padma river before being looted of all his belongings by itinerant river pirates. The lines that follow portray a life of utter destitution confronting the speaker as he progressively loses all his material wealth (Mojumdar 182: 1960). Strangely enough, his domestic comforts and marital bliss are invoked in the same lyrical strain immediately after. His life appears to be one of evident fulfillment and its 202 
celebration reaches a crescendo as he enters a state of non-differentiation between life and death. In fact, it could be argued that this climactic realization is replicated throughout the body of the poem in the interplays of plenitude and privation.

As Atindra Mojumdar (1960: 182) shows, the image of the vajranauka or thunderboat is a metaphor for the commute by the 'chitta' or the mind to the realisation of sunyata. The presence of the word in the opening line of the verse contributes to the obscure diction by striking a discordant, supernatural note in what is otherwise an ordinary riverine setting. This stark incompatibility promptly draws attention to itself and the image emerges as an exclusive iconic sign of the spiritual content it represents. The immediacy of the effect is further replicated in yet another inconsistent metaphor of the pirates who, despite looting the voyager of all his belongings, leave him curiously enriched. Here again, the sheer unlikely turn the events take emphatically communicates their inaccessibility to the laity while the penury wrecked by the marauding pirates is molded in the cast of the absolute renunciation brought about by 'advyaygyana' (Mojumdar 1960: 183) for the initiated.

In order to fulfill this iconic signification however, the literal language of the verses has to continually refer to something beyond itself: whether a hermetic puzzle or a reconciliatory spiritual truth. In the process, unlikely and tenuous parallels are drawn between images of a journey charted and lost in the void and destitution and fulfillment. Signification for the two most striking metaphors in the verse then, is a sustained act of being oriented towards these signifieds while also foregrounding the mismatch this orientation brings in its wake. This capacity to refer is founded on shared inferential grounds obtaining between the index and its signified-where the presence of one indicates the occurrence of the other. The vajranauka, for instance, comes to be a signifier connoting the mind's attainment of shunya by virtue of a shared field of comparison comprising tropes of mobility and journey. This interdependent referential relationship shared by the signifier and the signified finds a parallel in the Buddhist refutation of any inherent unity in a pre-conceived subject and attests to the unceasing play of a 'multiplicity of fluctuating phenomena' between subjects as being the causative origin of all meaning making process (Matilal 2001: 220).

Sandhayabhasha as a symbolic signifier furthers this referential function triggered by the index. Thus, the signified not only impacts the signifier but also transforms it. In this reading, the thunderboat is no longer a literal entity dissociable from the metaphor but an active participant in the meaning making process. It is in these lines that Mojumdar's interpretation of advayaygyana as a reconciliation in metaphor of the contradiction between penury and plenty at the literal level may be critiqued. Viewed as a symbolic signifier, the proximity of opposites in the verse is not a mere vehicle to convey the notion of advyaygyana but also its explication in situ. The signifier and the signified are thus triggered and modified by each other. This 
bears echoes of what Bimal Krishna Matilal (2001: 205) identifies as the 'dependent origination' thesis of Buddhist schools of thought. Quoting Nagarjuna, Matilal defines dependent origination as 'what (we call) emptiness [...] it is devoid of 'essence' (or, 'own-being' sväbhäva)'. He further continues, "those things which are dependently originated have no essential nature (i.e., no being of their own), for they lack their essential nature [...] they are dependent on causes and conditions (hetu and pratyaya)." The literal and metaphorical meanings in the verses too cannot stand alone in absolute autonomy and owe their origin and development to each other. In this interlinked saga of being, every signifier and signified remains devoid of a definable, self-generated essence and therefore lacks svabhava or one's own distinct nature.

The tenth charya verse by Kanhupada launches a direct invective against the rigidities of the caste system and social stratification prevalent in the composer's milieu. Through what seems to be a paean sung to a lower caste dombi or sex worker who resides far beyond the borders of the city, the poem attempts a reversal of caste hierarchies. The Brahmin priest she hosts as a customer is described as driven by lust and craving for the dombi even though he is never able to claim possession of her in entirety - due, not in the least, to his obsession with ritualistic purity. Her beauty thus remains ever elusive and well beyond his reach. This is in stark contrast to the Kapalika the narrator of the poem impersonates himself as. True to his itinerant and wayward way of life, the Kapalika decides to betroth himself to her and settle down for a life of marital bliss. That he does not embark upon this out of a sense of condescension is illustrated in the way he projects himself as an outsider, thereby affirming his solidarity with a social outcaste who nevertheless remains objectified as an embodiment of fantasy for the more privileged (Mojumdar 1960: 131). As Mojumdar suggests, she embodies Nairatmyadevi (goddess of no-soul) for the seeker of truth in the sahajiya tradition. The Brahmin's inability to win her heart is thus a commentary on her indifference towards all ritualistic practices. She bestows her wisdom instead only on someone like the Kapalika who renounces all trappings of social hierarchy and surrenders himself completely to the Dombi.

The figure of the Dombi as a representation of knowledge is both unusual and stark. A relation of resemblance between esoteric wisdom and a fringe inhabitant of the city is not immediately obvious and serves to render the verse obscure to the layperson. As a result, what is conveyed in the literal language itself becomes the end result of all interpretative exercise and the verse seems to mean exactly what it says. To visualise the Dombi in the likeness of Nairatmyadevi requires a yoking together of two disparate entities and is presumably a cerebral feat only the initiated sahajiya practitioners could hope to accomplish. For them, the Dombi is a corporeal form of Nairatmyadevi, and an immediate manifestation of the goddess' wisdom. The proximity in this case is therefore in the order of Peircean 'firstness' and the 
signifying figure of the Dombi stands in an iconic relation with the divinity she signifies.

At the same time, this likeness in image is furthered by the element of marginality common to both the Dombi and the Nairatmyadevi in the social and spiritual planes respectively. This forms a shared ground of comparison between the two and triggers the Dombi as a signifier. The semiotic relationship between the literal and metaphorical meaning in this case is a two-way signification and this qualifies the signifier as an indicative-rather than hermetic - sign. Here then, the literal meaning functions as an indexical sign for the metaphorical. Its suggestion of an unlikely unity between the two rests on a sustaining of their dissimilarities as outliers: where one is worshiped, the other is discriminated against. The link between the two therefore, is not an obvious presence but something that has to be worked out and arrived at. Added to the strained nature of this similarity, is also the question of assuming the marginal nature of the Dombi and Nairatmyadevi as a point of comparison. For all practical purposes, this appears rooted in a tradition of strong social critique of Brahminism that the sahajiya school offered (Mojumdar 79). Such a critique in fact extends well beyond the moral domain and has firm conceptual moorings. As Matilal (2001: 216) explains, what gets projected into the external world and creates an illusion of its immanent sentience are our desires or tanha. The crux of ignorance lies in projecting our own intentionality into the world around us and ascribing it an essential meaning. It is this meaning which we mistake as an inherent feature of the world out there and tend to associate our being with the same. In the verse in question, the Brahmin comes across as emblematic of the ignorant commoner who remains caught up in this web of tanha and is led astray despite his desire for salvation. The Kapalika, on the other hand, is able to see through the illusory world constituted by tanha and for that reason wins the Dombi's hand in marriage. Proceeding from a tradition of social critique, the story of the Dombi thus emerges as a symbolic signifier. It is in the body of this signifier at the textual level that the metaphorical meaning achieves concretion.

\section{Conclusion}

Based on the illustrations above, I offer the following features of iconic, indexical and symbolic metaphors in the Charya verses as concluding observations:

First, a provisional contiguity may be established between interpreting the iconic signifiers and sandhyabhasha on the one hand and indexical/symbolic signifiers and sandhayabhasha on the other. The iconic signifier is both remarkably transparent vis-a-vis the signified as well as doggedly selfreferential. This is in tune with the dual role played by sandhyabhasha as it both projects and effaces itself in a bid to render the diction of the charya verses obscure. As opposed to this, sandhayabhasha functions more as 
indexical and symbolic signifiers which orient the literal meaning towards the metaphorical.

Second, while the iconic metaphor attempts more of a faithful replication of its signified and emphasises on its proximity to the latter, the indexical and symbolic metaphors preserve and often foreground the departure of the signified while casting the relation within a framework of similarity. Thus, interpretation in sandhyabhasha can have only one of these two possible outcomes: either access into the metaphorical meaning or a complete lack of comprehension. On the other hand, to the extent that sandhayabhasha accommodates both differences and similarities, the reader might be led to comprehend the verses, albeit in a circuitous manner more in keeping with the Buddhist neyartha mode of imparting knowledge.

Lastly, the iconic, indexical and symbolic significations are less of types or categories and more of stages in interpretation. Thus, the literal meaning of the verse might appear with an immediacy typical of the iconic signifier while also linked in an indexical referential relation with its signified. Again, it is this referential function which allows the signified to reconfigure the signifier in radically different ways. Thus, the three stages complement each other and show significant overlaps.

\section{References}

BHATTACHARYA, VIDHUSHEKHARA. 1928. Sandhabhasha. The Indian Historical Quarterly 4. 287-296.

Fogelin, ROBERT J. 2011. Figuratively Speaking. New York: Oxford University Press.

GANERI, JONARDON. (ed.) 2002. The collected Essays of Bimal Krishna Matilal. New Delhi: Oxford University Press.

Matilal, Bimal Krishna. 2002. A Critique of the Madhyamika Position. In Ganeri. 203-212.

MATILAL, BIMAL KRISHNA. 2002. Nyaya critique of the Madhyamika position. In Ganeri. 213-229.

MOJUMDAR, ATINDRA. 1960. Charyapada: A Treatise on Earliest Bengali Buddhist Songs. Kolkata: Naya Prokash.

PeIRCE, Charles SANDERS. 2011. Logic as Semiotic: The Theory of Signs. In Justus Buchler (ed.), Philosophical Writings of Peirce. 98-119. New York: Dover Publications Inc.

RAmANUJAN, A. K. 2006. Three hundred Ramayanas: Five Examples and Three Thoughts on Translations. In Vinay Dharwadkar (ed.), The Collected Essays of A. K. Ramanujan. 131-160. New Delhi: Oxford University Press.

RICOEUR, PAUL. 1978. The Metaphorical Process as Cognition, Imagination and Feeling. Critical Inquiry 5. 143-159. Online: http://www.jstor.org/stable/ 1342982. 
Sandhayabhasha Metaphors in the Charyapada

SHASTRI, HARAPRASAD. 1916. Hajar Bochorer Purano Bangala Bhashay Bauddha Gaan o Doha. Kolkata: Bangiya Sahitya Parishad Mandir.

*** $*$ 